\title{
*PLASTIC SURGERY IN THE REHABILITATION OF THE LEPROSY PATIENT
}

J. D. KanakaraJ, M.B.B.S.

The principal cause of public horror towards leprosy appears to lie in its mutilations. If this fact is understood it is then easy to explain the paradoxical situation wherein one finds an early case of lepromatous leprosy with hardly discernible lesions but with a high bacteriological index and a wide range of infectivity being permitted to mingle in society freely, while another, a disease arrested and non-infective case with a certain number of residual mutilations, is harassed and hounded. The significance of this is felt when these patients are being returned to society in the final stage of their rehabilitation.

The advent of the sulphones and allied drugs has undoubtedly revolutionised the therapeutic outlook in this disease. We are now in a position to offer to the average patient a method of treatment by means of which the clinical lesions of the disease are to a certain degree abolished, his bacteriological index reduced to zero, and an opportunity afforded to him to retrieve himself from various dislocations resulting from the disease, and to retum to and occupy his rightful place in society. It is in this process of recovery, physical, moral and economic that rehabilitation plays an important part.

In analysing the psychology of the leprosy patient one is confronted with the clear evidence of psychic trauma that is present in almost every case. Each individual believes that he or she has been the victim of a cruel fate, and, according to his or her own belief, a malignant disease has visited him or her: and he or she only sees in the dark future a separation from family and friends, unemployment and banishment from society as a result of these tensions. These alterations in behaviour patterns have produced the spectacle of a lonely and frustrated figure, more sinned against than sinning, and the patient loses his confidence, his faith in himself and his self-respect. To rescue the patient from this psychological abyss is yet another important function of rehabilitation.

\footnotetext{
- A brief form of this paper without its scientifio portions was read at a Conference of District Secretaries and Select Leprosy Workers under the auspiocs of the Find Kusht Nivaran Sangh (Indian Leprosy Relief Association) at Madras on September 26th, 1952: and the clinical photographs were among others exhibited in the Scientific sections of the All India Surgeons Conference, Vellore, December 30th, 318t, 1952 and January 18t, 1953 and at the All India Leprosy Confe ence at Puri, January 4th to 6th, 1953.
} 
In my observations of the patients of the Government Lady Willingdon Leprosy Sanatorium over a period of twenty-one months, I found this factor of psychic trauma very much in evidence. In addition to this, psychic trauma appeared to be directly proportional to the degree of mutilation present in the patient. During this period, as many as three hundred patients were discharged from this sanatorium as "disease arrested" and it has been noticed that, while the relatively mutilation-free patient has been eager to go out and return to his home and to his occupation, the patient with a certain number of residual mutilations exhibits a hesitancy, sometimes amounting to reluctance, which cannot be missed. On closely questioning these patients I found them obsessed with doubts as to whether and how society would take them back. This led me to conclude that a situation was present where a final step in rehabilitation was necessary to rectify as far as possible, the disfigurements that were obstructing his return to society.

In analysing the disfigurements that exist in these patients I find they are anatomically distributed as follows. The ears are large and overgrown due to nodulation and supernodulation. The nose is deformed and distorted, and this may range from simple nodulation of the alæ nasi to frankly depressed bridges, and many intermediate types. Facial paralysis, ptosis of the eyelids, ectropion and leucomas complete the alterations in the physiognomy. Gynæcomastia constitutes another grave disfigurement, with the additional disadvantage of the " reproach of effeminacy." Keloids may exist anywhere, and may be the result of trauma, ulceration or burns. Deformities of hand or foot complete the picture.

Work was undertaken at the Government Lady Willingdon Leprosy Sanatorium, Chingleput over a period of twenty-one months to apply various corrective procedures to some of the deformities listed above, with a view to finding out their feasibility in leprosv patients; at the same time was kept in mind the underlying motive of rehabilitation.

The patients of the Government Lady Willingdon Leprosy Sanatorium fall into two broad groups: (I) a small static group which comprises those patients who are far advanced in their disease and who are blind and crippled, and in whom the question of rehabilitation does not arise, and also others who, being unsuitable for treatment with the new drugs, have been restored by hydnocarpus therapy, in whom the period of treatment is thus prolonged and the prospects of " arrest " and rehabilitation greatly reduced. (2) A large dynamic group which consists of the majority of patients who are either of the early lepromatous or moderately advanced lepromatous types. (No non-lepromatous cases are 
admitted in the sanatorium, as the institution is primarily meant for the segregation of infective cases). It is among these patients that rehabilitation programmes are intensively applied, as under the present day therapeutic regime with sulphones many of them are discharged. It was to this group that rechabilitative plastic surgery was applied over a period of twenty-one months, and the deformities or mutilations that received attention were only those that occur commonly among them, namely, gynæcomastia, deformed noses and unsightly ears. These are dealt with individually below. The selection of cases was always made from a rehabilitative angle, that is, the patient had to be clinically arrested or at least his clinical lesions controlled under adequate sulphone therapy: his bacteriological index had to be zero or near zero: and finally the patient had to be suitable for the particular plastic procedure contemplated.

\section{GYNACOMASTIA}

Webster recognised three distinct pathological types in this condition. In type I there is periductal connective tissue hypertrophy alone, and the gland is felt as a firm discrete nodule under the nipple. In type II there is an additional hypertrophy of adipose tissue, and the gland is less palpable. In type III the adipose tissue alone hypertrophies and the gland cannot be felt at all. The essential features of Webster's operation are (a) a semi-circular intraareolar incision, (2) a sub-areolar dissection of the breast, (3) delivery through wound in single or multiple pieces, (4) hæmostasis and (5) closure. In the second step, viz., dissection of the breast, Webster varies his technique with the type of tumour he is dealing with. In the type I group of cases where the mass of enlarged ducts and periductal tissue alone comprises the tumour, the dissection is along the surface of the gland entirely. In the intermediate type, the amount of fat within the mass is slight or considerable. When the latter condition is met with, the dissection is along the gland superficially, but as this plane cannot be maintained at the periphery and sometimes on the undersurface, a certain amount of hypertrophied fat is also excised by him. When the mass is so large that no residual fat has been left over the pectoralis fascia, there is a possibility of the nipple becoming adherent to the pectoral fascia. To prevent this, Webster performs a repair wherein he closes in a slight amount of fat under the nipple. In type III he advocates a cone-shaped resection of the breast to reduce its prominence, and performs a similar repair if necessary.

In leprosy the pathological nature of the gland appears to be a hypertrophy of breast tissue alone. To the naked eye the breasts 
excised by me were white, firm and well defined. Microscopic sections would have revealed their true nature but the necessary facilities were not available. There was no apparent increase in fat, and the subcutaneous fat was in direct proportion to the general adiposity of the patient.

The operative procedure adopted by me in these cases is based on a consideration of the anatomy of the part. It is similar to the procedure adopted by Webster for his Group I cases to which gynæcomastia of leprosy appears to belong, except for one or two minor details which will be mentioned later.

In considering the anatomy of the breast, it is seen as a hemispherical object with its base resting on loose areolar tissue and attached to it by means of the ligaments of Astley-Cooper. On its curved surfaces it is similarly attached to the skin by ligamentous tissue which traverse the subcutaneous fat. Taking these anatomical factors into consideration, the resection of the gland is performed along a plane close to the gland (see diagram). This "white line " constitutes a practically avascular plane, and a resection along this simplifies the procedure considerably.

The actual operation is done as follows: The assistant stretches the areola and the surrounding skin. A semi-circular incision is placed a fraction ( $\left.f^{\prime \prime}\right)$ within the areola, and measures not more than an inch or an inch and a half at the most. It is most conveniently placed inferior to the nipple, but again can be situated anywhere on the circumference of the areola. The main difficulty is that the operative field is barely a square inch, and much of the resection is literally done through a hole, but with good vertical traction of the gland by means of tissue forceps, the plane of resection is elevated to the surface of the skin, while skin retraction widens the operative field much more than expected.

After making the incision, the plane of resection is sought for, The gland is identified and is freed a little from the skin and subcutaneous tissues. A pair of blunt scissors is then introduced along this plane and the blades opened out in all directions. By means of this procedure, the ligaments attaching the gland to the skin are torn and the gland is freed from its cutaneous attachments and its mobility as a consequence increased. The dissection is then commenced and progresses radially downwards, outwards and inwards in the first instance. Blunt dissection most often suffices except in rare instances where there has been an old peri-mastitis, or where AstleyCooper's ligaments are dense and hypertrophic. As the gland is dissected and mobilised, it is delivered through the wound in order to keep the field clear for further resection. After the gland has been thus freed from its attachments to the skin on three sides, the 


\section{Plastic Surgery in Leprosy}

base is reached, which is then readily raised by blunt dissection from the underlying loose areolar tissue. The dissection is now directed upwards, where once again gland connected with skin is met with, and the dissection is proceeded with as before towards the areola till the junction of the skin with areola is reached. At the upper and outer quadrant some difficulty may be experienced, by virtue of the axillary tail. At this stage the whole gland lies outside the wound, with its apex connected to the areola and the nipple. The gland is then excised, leaving a button of gland tissue under the nipple. The object of this button is to prevent the nipple from puckering and retracting inwards. I have differed from Webster in this respect in leaving a larger amount of gland tissue, as I feel that even the slightest puckering would vitiate the cosmetic result. The wound is then primarily closed with close, interrupted cotton sutures, and a firm dressing applied. No drainage is instituted although the condition may theoretically warrant it. The wound heals by first intention, and the resultant scar is hardly visible, being camouflaged in the pigmented areola.

The important points to be observed in this operation are:

(I) to aim at removing the gland, the whole gland and nothing but the gland. As a result of this, the entire subcutaneous fat is preserved. The benefit of this is realised from the cosmetic angle. It is the subcutaneous fat that lends the normal contour of the chest, and any removal of it results in a " caving in " effect which is disastrous cosmetically to the patient, for where he had a convexity in the shape of the gland, he now would have a concavity, Also an additional advantage is this. The large area of skin involved depends for its nutrition and blood supply on the subcutaneous fat; hence its careful preservation prevents sloughing and gangrene of skin or nipple, a finding recorded in one of Webster's cases.

(2) to maintain the dissection of the gland along the "white line". By doing so, a practically avascular resection is achieved. Bleeding is reduced to a minimum. The advantage is this: the operation is by itself an irksome procedure, as separating the gland subcutaneously, mobilising it, and delivering it through the extremely small wound is a trying process, and calls for some manual dexterity and a good deal of patience. If in addition to this, one has to peer through a small hole and attempt to locate, catch and ligate bleeding points, the whole procedure becomes an unduly taxing affair. In the " white resection" there is no spurting but a mere oozing. Vigorous mopping clears the field and prevents difficulty in continuing the dissection. In no case of my series was 
a single ligature applied. A sucker would be most helpful in clearing the field and preserving good vision, although I had not the services of one.

The obvious disadvantage of this procedure is the possible formation of a hæmatoma, especially in view of the fact that a dead space is left behind with raw areas on all sides. Sometimes there is a fair amount of oozing, and a hæmatoma should therefore always be expected, though a firm bandage usually suffices as a preventive. Actually out of the series done by me, two developed a hæmatoma, serving to illustrate the point. The first case had to be aspirated once, and Io cc. of bloody fluid was withdrawn; in the other case aspiration was done twice and $40 \mathrm{cc}$. of similar fluid removed. The point of interest was that the hæmatomas appeared only on the $5^{\text {th }}$ day after operation. I am inclined to believe that a secondary factor operated in these cases and it is most probably this. Both the cases were on the right side in righthanded persons, and as the patients were more or less semi-ambulant after the operation, it was presumed that activity associated with their right hands encouraged some late oozing, and also disturbed the firmness of the bandage. As a result, a further precaution was added by immobilizing the corresponding arm by means of a cuff and collar. No further hæmatomas have been noted. In any case, daily opening of the dressing and looking for a hæmatoma should be done. The possibility of hæmatoma formation should not, however, deter one from employing this operation, as it is easily relieved by aspiration and can be controlled by adequate chemotherapy.

Gynæcomastia constitutes a problem in leprosy. It is seen in a small percentage of cases of lepromatous leprosy. Its exact pathology is yet unknown and attempts to treat it medically have failed. Even under sulphone therapy it has been noticed over a period of five years that there is no regression. Surgical removal constitutes the most satisfactory method of treatment. In the surgical management of this condition in the healthy, there has been a gradual evolution of a cosmetic approach with Webster's technique as a culmination of this. Webster in 1946 was the first to advocate an intra-areolar approach, and in doing this he offered a practically scar-less operation. In a series of 37 breasts done by him over a period of 12 years his results were uniformly excellent.

This technique was tried by me on patients of the Govt. Lady Willingdon Leprosy Sanatorium in the course of this work and in a series of I9 breasts over a period of 2I months I have obtained equally good results. I would strongly advocate the 

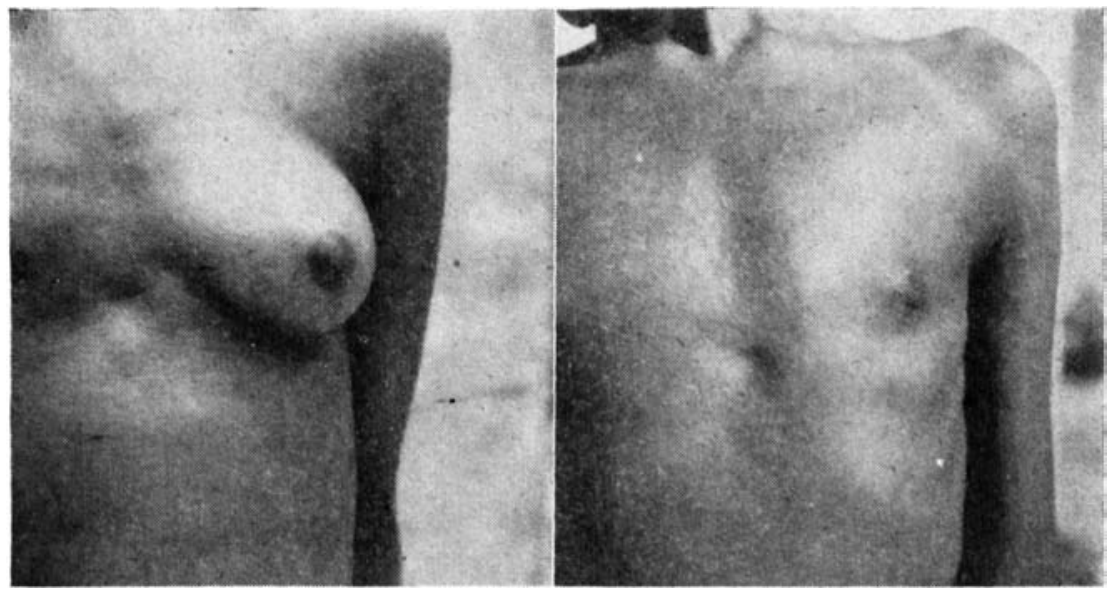

Case No. I. Before operation.

('ase No. I. After operation.

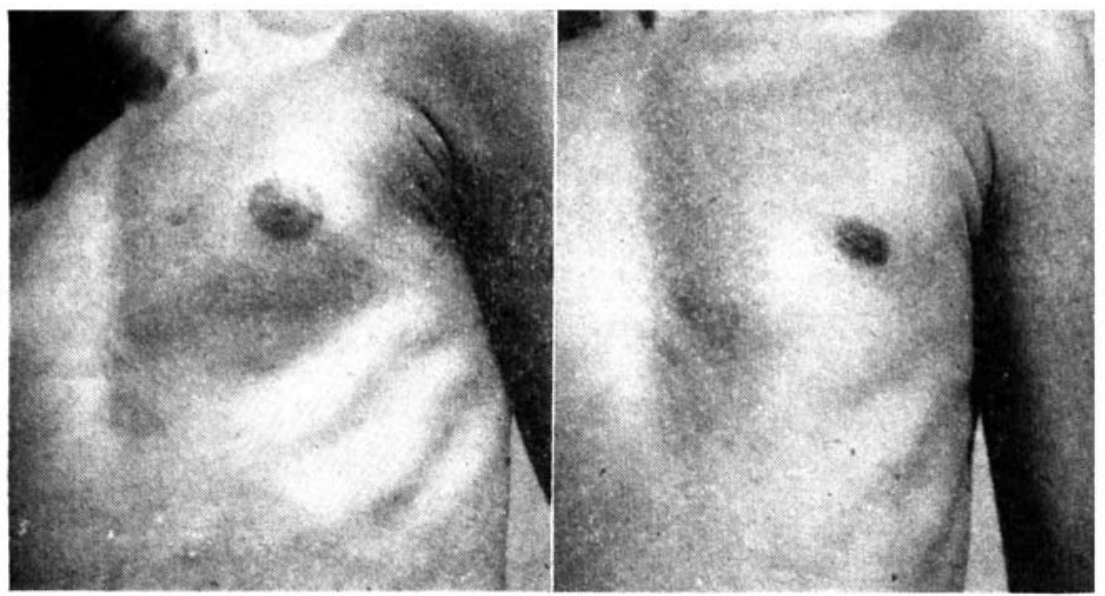

Case No. 2. Before operation.

Case No. 2. After operation.

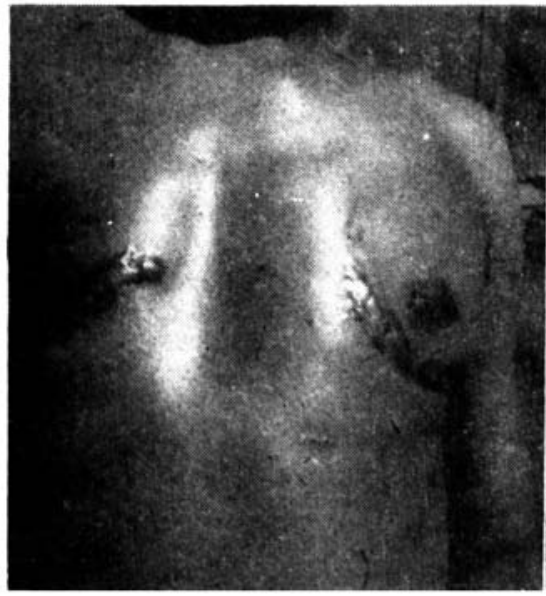

Case No. 3. Before operation.

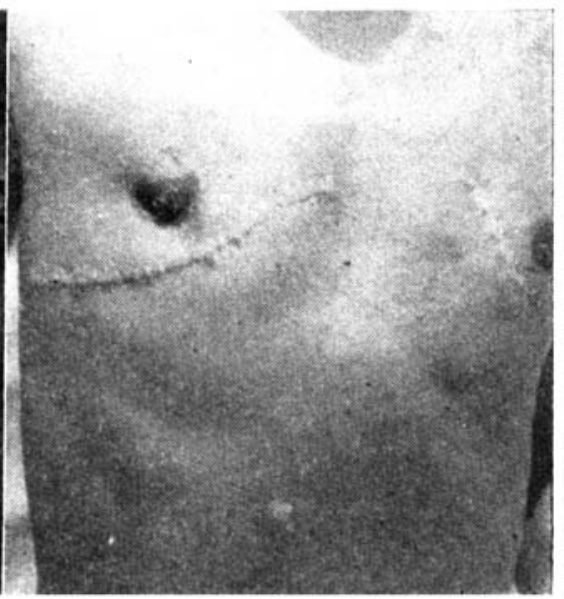

Case No. 3. After operation. 
adoption of this technique in all leprosaria and hospitals where surgical excision in these patients is carried out.

Two specimen cases and a contrast case are presented below:-

Case No. 1. V. aged 20-moderately arlvanced leproma-duration of leprosy 3 years-gynxcomastia left side, duration 2 years-has spermatorrhea on and off-on examination the left breast enlarged to the size of a lactating breast-no swelling or tenderness of testes or cords. Under local anaesthesia the gland was excised using the above technique. There was no post-operative complication. Sutures were removed on the seventh day and the cosmetic result as seen from the clinical photograph was very good. The point of interest was that the gland was removed in one single piece.

Case No. 2. B. aged 30 years-moderately advanced lepromaduration of leprosy is years, duration of gynacomastia 2 years-had frequent attacks of spermatorrhea before onset of breast swellings. The gland was similarly excised as above. Result good. The case is mentioned as it is a small enlargement as opposed to rase No. 1. In such cases the technique is easy to apply and the operating time is not longer than half an hour.

Case No. 3. This patient had a bilateral gynxecomastia four years ago for which he was operated on $24-8-48$ and $11-9-48$. Gaillard Thomas method was applied. In 1952 the patient presented himself with dense keloidal formation of his scars (see clinical photograph). In his case record there is no mention of postoperative sepsis or lepra-reactions to account for his keloids. Such a development produces a worse disfigurement than the condition itself. In June 1952 his keloids were excised and plastic repair of his chest wall performed. The result was very good. This case is mentioned to demonstrate a possible sequel when an extra-areolar route has been employed. There is no possibility of keloid formation in the intra-areolar operations.

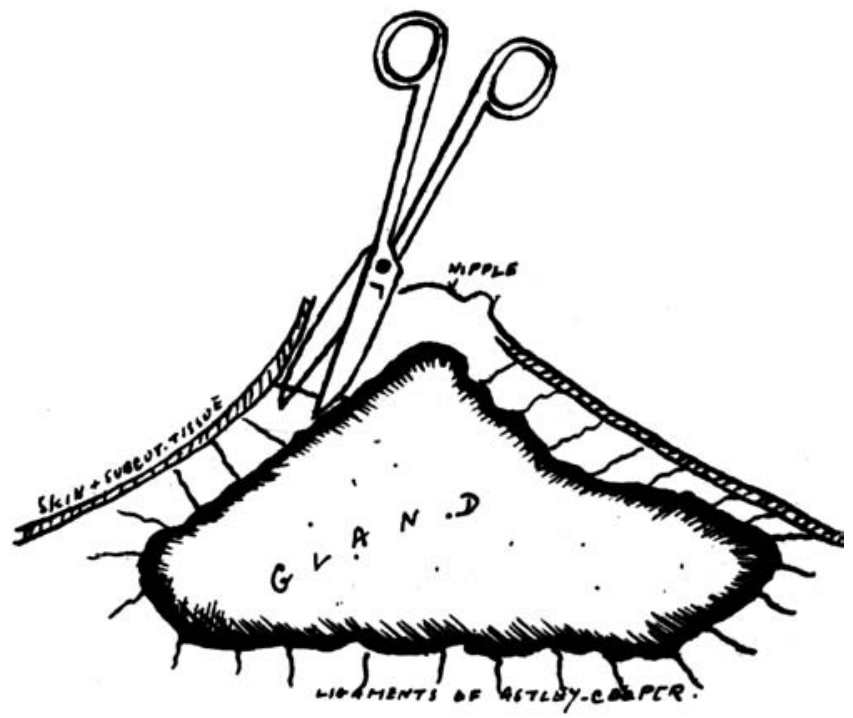

STAGE I

The incision has been made, the gland identified by its white surface, and is dissected upwards through the wound from overlying skin and subcutaneous tissue. 


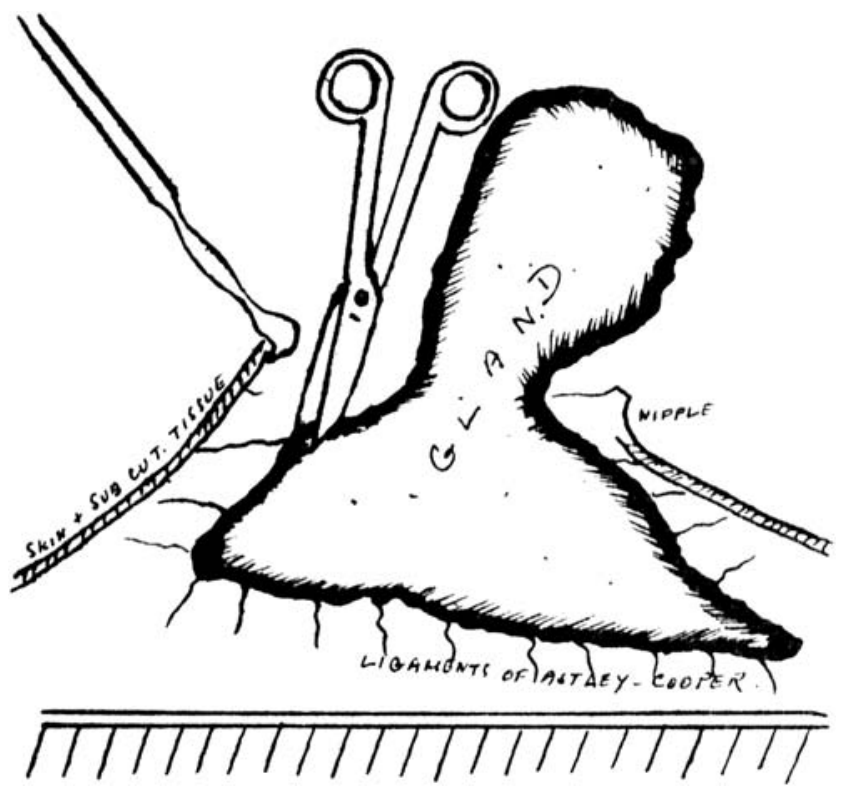

STAGE II

The dissection adhering strictly to the white line proceeds radially inwards, outwards and downwards. This frees the outer and inner lower quadrants.

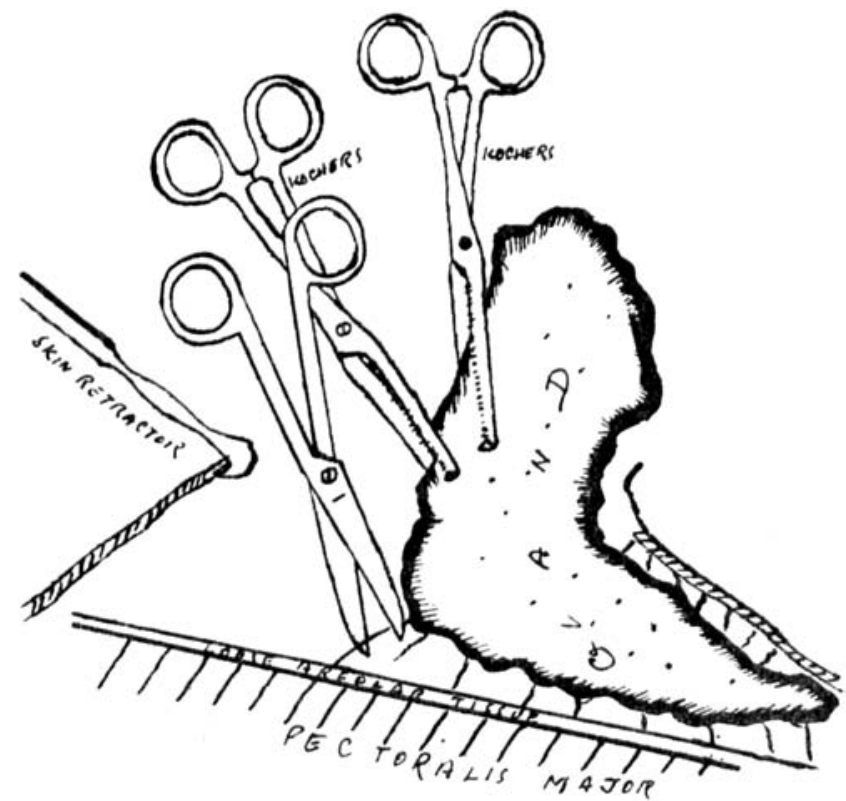

STAGE III

The base is now reached which is separated from underlying muscle and alveolar tissue. 


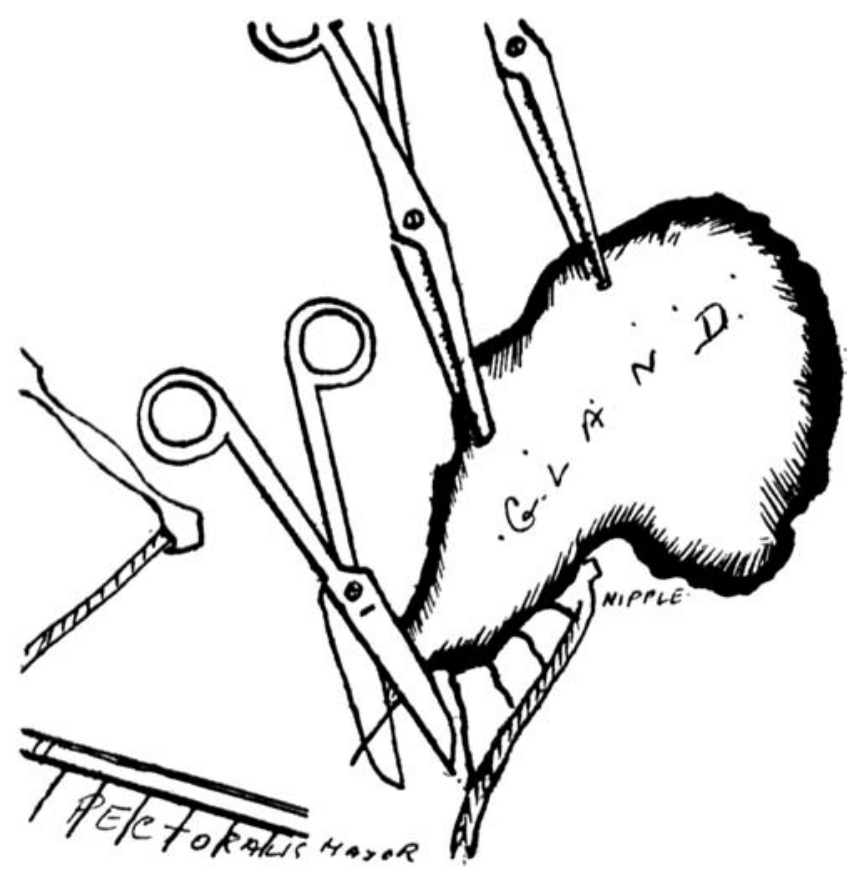

STAGE IV

The gland having been immobilized and delivered through the wound, now leaves the upper, outer and inner quadrants attached to skin and subcutaneous tissue. This is separated as above.

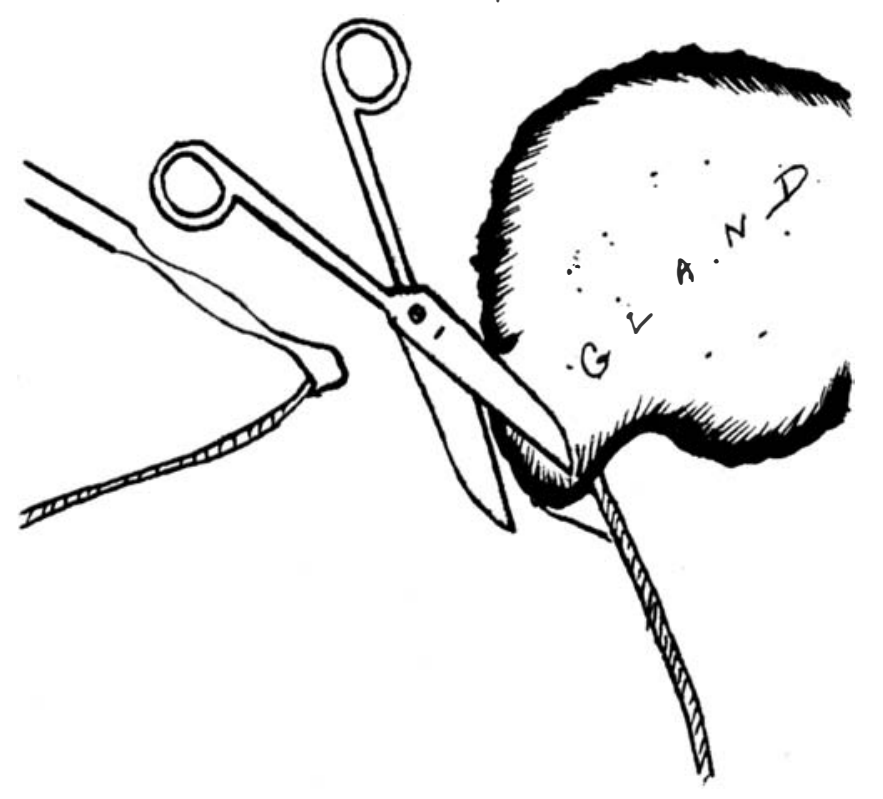

STAGE V

Here the entire gland lies outside the wound. The gland is then amputated, leaving a button. Wound closed, firm bandage. 
Instruments required: Knife, dissection forceps, a pair of skin retractors, two pairs of Kocher's forceps, one pair scissors, straight with blunt points $\left(5 \frac{1}{2}{ }^{\prime \prime}\right)$, Mayo's needle holder, curved cutting needle, cotton sutures, swabs.

\section{THE EAR}

In lepromatous leprosy the ear is thickened and enlarged, and this may be due to diffuse infiltration or to nodulation and super nodulation. The effect of this is to give a thick and coarse ear to the patient which is both ugly and unsightly. Under sulphone therapy the nodules regress and the infiltration clears up, but the tissues do not decrease in size though they may shrink or become loose and pendulous, particularly the lobes. When the nodules have ulcerated, marginal defects result, but this is quite rare under sulphone therapy. This constitutes a deformity not only by virtue of its physical characteristics, but also because it is a common stigma associated with the disease, known to and easily recognised by the laity.

In the past, surgical excision of the redundant tissues was practised under the name of "trimming." The procedure has been in most cases simply to apply the blades of curved scissors, and to seal the wound with Friars balsam. The cosmetic results of this were not always satisfactory. It is felt, however, that the time has come to raise this procedure to the level of the fine art of plastic surgery, particularly as under sulphone therapy many patients are being discharged to return to society. Keeping this in view, a technique contemplated to reconstruct the ear in such a manner as to restore the size and shape of the ear to normality, without revealing the evidence of surgery, was developed and practised on these patients.

The following is the technique: Two parallel incisions are made, one anteriorly and the other posteriorly on the margin of the ear including the lobe, the shape according to that which is required. The posterior incision is $\frac{1}{8}$ " more medial than the anterior incision. This is to hide the final scar which then becomes displaced posteriorly. The tissues between these two incisions are excised in such a manner that the anterior and posterior edges slope inwards. Occasionally some cartilage may also have to be excised, everything depending on the size and shape of the ear which is desired. There is some bleeding, but usually it is not necessary to ligate any bleeding points. The two edges are then neatly opposed and sutured with fine cotton as close as possible. The " bites " should be small and as many as 40 sutures may be required for each ear. If these precautions are taken the result is very good, the ear looks quite normal and the scar-line is so thin that it is hardly seen. Two other 
factors must be borne in mind. One concerns symmetry of both ears. If one is not confident of judging symmetry by visual judgment alone, an outline of the ear that has been already done may be taken on a piece of tin or any other suitable sterilisable material and used for the other ear. This was not done in our series and I find that visual judgment is quite satisfactory. Another point is that it is a sound rule to do the difficult or more deformed ear first. This renders the second operation, particularly with regard to symmetry, very easy. Also a precaution to be observed is that in re-shaping the lobe, too much tissue should not be taken off, as this renders the apex of the ear prominent and gives it the appearance of " rabbit ears." A specimen case is presented.

Case No. 4. G. age-I4 years-moderate leproma-Bacteriological index on admission 4.12 in October 1950-October 1952 Bact. Index 0.3 after continuous therapy with oral diamino-diphenylsulphone. His ears were heavily nodulated and looked unsightly. He presented himself for operation as he complained of harassment during his annual visit to his village on leave from the sanatorium. Further he alleged that he had to walk ten miles to his village from the railway station as the buses refused to take him on account of his appearance. Consequently his ears were repaired using the above technique. The result was very good and his subsequent excursions into society were uneventful. The patient awaits discharge and looks forward to return to work in the fields as he comes from an agricultural community.

\section{The Nose}

The following basic types are recognised in the alterations of the nose in lepromatous leprosy, depending on the stage and degree of the disease in which it is arrested. In type I there is a nodulation of the alæ nasi which produces changes in the shape and size of the nostrils. In type II where depression of the nose is the characteristic feature, the pathological changes have been more severe. This depression can be anatomically subdivided into (I) superior (2) intermediate, and (3) inferior sub-types. In the superior type of depression, the bridge of the nose is irretrievably lost as extensive intra-nasal ulceration ultimately leads to erosion and destruction of the nasal bone. This condition is most likely the result of secondary infection particularly with maggots causing an osteomyletis of the bone, which then sequestrates, and these are discharged along with the nasal secretions. In the intermediate type the septum of the nose has been eroded as a result of ulcerations, and the nose sinks over the corresponding area. When this occurs in the middle, the sinking in of the centre of the nose causes an approximation of the bridge and the tip of the nose, which results in the tip becoming unduly tilted. In the inferior type of depression, the lower part of the septum becomes defective with the result that the 
tip collapses giving rise to a flat nose. Further the intrinsic cartilage of the alæ nasi may become eroded and replaced by fibrous tissue, which causes puckering and flattening of the nostrils.

It is necessary to recognise the above types, as each type calls for a different technique and approach in dealing with the condition. In type I it suffices to excise the nodules and pare down the tissues with due consideration for symmetry and contour of the nostrils. One case (case No. 5) is presented below.

In type II, superior depression where the bridge of the nose is lacking, bone-grafting is the operation of choice. A case in which this was done is presented below (case No.6). The technique was to remove a graft from the tibia and transplant it to the nose. The tibia was chosen as it is easily accessible and serves the purpose well. Further, the anterior border of the tibia gives just the required shape (boat-shaped) to the graft. A median incision is then made over the nose and a bed prepared for the graft. The graft is then placed in position and sutured over. As the nose is an immobile part, it was felt that internal fixation was not necessary and this was achieved by adhesive strapping to give external support. In the one case, clinically and radiologically examined, the graft had taken.

In type II, intermediate and inferior type of depressions, cartilage grafting suffices and gives satisfactory results both early and late. The graft is taken from the ear, and the site is the posterio-superior angle of the ear where the natural shape of the cartilage is such that a boat-shaped piece of cartilage is easily secured. An incision about an inch long is placed vertically at this angle on the posterior aspect of the ear, and the required piece of cartilage excised. The wound is then closed, leaving the defect in the cartilage as it is, as no untoward effect results from this. The cartilage is then transferred to the required site according to the deformity. Where the alæ nasi are sunk and distorted, flat, oblong pieces of cartilage are required, and these have to be taken from the posterior aspect of the pinna of the ear. In general it must be remembered that postleprotic tissue is very friable and "crumbly", and sutures often cut through. For this purpose, fine instruments and suitable suture material are required. We used cotton for all our cases, and we find it suits the purpose well.

Case No. 5. G.S. -aged 12 years-moderate leproma-Bacteriological index on admission on I-II-5I was 4.5I-Under sulphone therapy steady and gradual improvement, and after a year's treatment B.I. was reduced to $0.6 \mathrm{I}$. There was nodulation of his alæ nasi which were unsightly-had no other deformities. In view of his steady improvement, on 29-4-52 a cosmetic operation was performed as described above. The result was very good. 
Case No. 6. P.-aged 23 years-moderate leproma-B.I. on admission on 8-3-49 was 3.I2. Had been on intensive sulphone therapy from II-5-49 and showed steady improvement. In the early period of his disease (since 1936) patient had blocking of his nose, epistaxis and a foul discharge. He showed a deformed condition of the Type II intermediate as described above. There was approximation of the bridge of the nose with the tip so that the nose was shortened and the tip tilted. Under a local anaesthesia a cartilage grafting as described above was pertormed. Both early and late results were very satisfactory.

Case No. 7. W.-aged 29-date of admission 24-3-50-advanced leproma-relapsed slightly as had been previously in the institution for seven years from 1942 to 1949 and was discnarged as a " quiescent case." Was placed on hydnocarpus therapy at his ewn request. B.I. in October I952 was 0.69. He had a frankly depressed bridge of nose. On I.7.52 bone grafting of his nose as described above was performed. The result was far beyond expectations. The graft " took" and the patient's appearance is very much improved. The patient's outlook has also changed considerably with this and he is now eagerly awaiting his discharge to seek employment. An additional point of interest in this case was that the operation, including the taking of the graft, was performed under local anaesthesia only. There was no means of inaesthetising the bone by this method and the taking of the graft caused no pain or discomfort to the patient, the only thing complained of being an abnormal vibration sense.

\section{WORK DONE}

During the course of this work which extended over a period of twenty-one months as many as 39 plastic operations were performed as follows:-

\begin{tabular}{|c|c|c|}
\hline Webster's operation for & r gynæcomastia .. & \\
\hline Simple ear repair $\quad \ldots$ & $\ldots \quad \ldots$ & \\
\hline Simple nose repair ... & $\begin{array}{ll}\ldots & \ldots\end{array}$ & $\ldots$ \\
\hline Compound nose repair & $\begin{array}{l}\text { Cartilage grafting } \\
\text { Bone grafting }\end{array}$ & \\
\hline
\end{tabular}

A greater number of operations could not be performed for various reasons, although they were very much in demand among the patients. Also, in all cases done, the criteria of selection was strictly adhered to, and this factor naturally limited the number. All cases received careful pre-operative preparation. They were all performed under local anaesthesia. A generous quantity of penicillin was expended on these patients; all cases getting 200,000 units of the drug daily for five days from the day of the operation. In only one instance did infection supervene, and this was in a cartilage grafting of the nose, where the wound was infected and the cartilage graft extruded through the wound on the second day. In all other cases the results were very good and uncomplicated by infection. Many of the rules of plastic surgery were broken in the course of the work, as the cases were done in a common theatre wherc many septic operations were also performed, and the cases placed in a common ward under similar conditions. In the circum- 
stances it is surprising that infection was not present more often. I owe this largely to the protective umbrella of penicillin.

\section{Conclusions}

As a result of this work and the observations made on the patients of the Govt. Lady Willingdon Leprosy Sanatorium over this period, the following conclusions are put forward for consideration:

(I) that a factor of psychic trauma is present in leprosy patients and this is induced by the character and nature of the disease and the effecls it has had on them, particularly in their altered relationship to society.

(2) that the irtensity of this psychic trauma is in direct proportion to the degree of mutilations present.

(3) that a situation is present where the final rehabilitation of the patient is prevented by his disfigurements.

(4) that plastic surgery can to a certain extent relieve this situation by removing or reducing these disfigurements and thus facilitate his re-entry into society.

In conclusion it must be admitted that the work done in this connection has been only of a preliminary nature, and the cases on which some observations have been made are not numerous, but this paper has been written in the hope that serious consideration will be given to this aspect in the treatment and rehabilitation of leprosy patients.

\section{ACKNOWLEDGEMENTS}

I wish to thank Dr. H. Paul, M.B.B.S., Medical Superintendent, Govt. L.W.L. Sanatorium for having afforded me the facilities for doing this work and for his encouragement: to Sri N. Ramakrishna Iyer, Welfare and Rehabilitation Officer for his collaboration and to my wife, Dr. (Mrs.) M. Kanakaraj, B.Sc., M.B.B.S., for her assistance in the theatre and wards.

\section{REFERENCES.}

1. J. P. Webster: Mastectomy through an Intra-Areolar incision. Annals of Surgery, 1946, 124, 557.

2. KANAKARAJ: Webster's operation for gynæcomastia as performed on leprosy patients. Paper read at All-India Leprosy Conference, Puri, Jan. Sth, 1953.

3. Ibid-Lepra-Surgery-Its principles, problems and present outlook. Antiseptic, Aug. 52, Vol. XIIV, p. 569. 